\title{
Time Series Stochastic Properties Of Growth Miracles And Growth Disasters
}

\author{
Rafael Avila, (Email: rafael.avila@iesa.edu.ve), Banco Provincial and IESA, Venezuela \\ Hugo J. Faria, (Email: hugo.faria@iesa.edu.ve), IESA, Venezuela \\ Hugo Montesinos-Yufa, (Email: hmm@uchicago.edu), University of Chicago \\ Daniel Morales, (Email: dmorales@uma.edu.ve), Monteavila University, Venezuela
}

\begin{abstract}
Preliminary findings of this research suggest significant stochastic properties differences between growth miracles and growth disasters. Miracles' real GDP per capita exhibit at least one unit root whereas disasters' is either stationary or has a negative unit root. Average growth rates appear to be significantly different. Average population growth rate is stationary for disasters, for miracles the existence of a negative unit root cannot be rejected. Consumption for miracles is either stationary or tends to decline, for disasters is stationary or tends to increase. Investment average and volatility are apparently significantly greater for miracles. Government expenditures for disasters are non stationary, for miracles are stationary with an incipient tendency to decline. Moreover, average government expenditures apparently are greater and more volatile for disasters. Finally, openness is stationary for disasters and for miracles it has at least one unit root.
\end{abstract}

\section{INTRODUCTION}

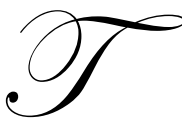

he literature on stylized facts of economic growth characterizes as growth miracles economies with exceptionally good performance, Jones (2002) and Barro and Sala-i-Martin (2004). Specifically, 10 countries that over the period 1960-2000 experienced average growth rates of their real income per capita, adjusted for purchasing power parity, in the range of $4.1 \%$ and $6.4 \%$ are considered growth miracles. The fastest growing economy is Taiwan with an average growth rate of $6.4 \%$. Taiwan's income per capita in 1960 was of $\$ 1,430$ and in the year 2000 it was $\$ 18,700$ increasing by a factor of 13 in the span of 40 years.

Economies, however, that over the same period experienced on average negative real income per capita are called growth disasters. With known data there are 16 countries in this category, 14 are located in the sub-Saharan African region and two, Nicaragua and Venezuela, are located in Latin America. The slowest growing country, Democratic Republic of Congo, former Zaire, had in the year of 1960 a real income per capita of $\$ 980$ and in 1995 of $\$ 320$ with a growth rate of $-3.2 \%$.

The purpose of this research is to assess the time series properties of growth miracles and growth disasters and ascertain if meaningful differences can be established. This paper examines the temporal behavior of variables that according to the theoretical growth literature impact an economy's performance. The results attempt to augment the stylized facts of economic growth and cast light on policy issues.

Preliminary results suggest that overall significant differences exist between growth miracles and growth disasters. The rest of this paper is organized as follows. The next section contains data sources and section IV discusses the methodology. Section $\mathrm{V}$ reports the major results and the final section concludes and suggests avenues for additional testing and future research.

\section{DATA}

The data source of this study is Heston, Summers and Aten (2002), Penn World Table Version 6.1. The variables studied, over the period 1960-2000, are Real GDP per capita (RGDPL), Growth Rate of Real GDP per 
Capita (GRRGDPL) and Population (POP). In addition and as a fraction of GDP, this paper looks into the stochastic properties of Consumption (KC), Investment (KI), Government Expenditures (KG) and Exports plus Imports (OPENK).

The economic time series aforementioned correspond to economies exhibiting an average growth rate of the real GDP per capita in excess of 5\% over the 1960-2000 period. These economies are Taiwan, Singapore, South Korea, Hong Kong and Botswana. This set of countries is known in this paper as Super miracles. Additionally, economies showing an average growth rate between $4 \%$ and 5\%, Mini Miracles, are Thailand, Cyprus, China, Japan and Ireland.

Economies experiencing negative average real GDP per capita growth, between $-1 \%$ and $-1.7 \%$, over the 1960-2000 period are Central African Republic, Niger, Angola, Nicaragua, Mozambique and Madagascar. This set of countries comprises the Super Disaster Group. Economies enduring an average growth rates between 0\% and -1\%, Mini disasters, are Nigeria, Zambia, Chad, Comoros, Venezuela, Senegal, Rwanda, Togo and Burundi.

\section{METHODOLOGY}

\section{Conventional Univariate Augmented Dickey-Fuller (ADF)}

The methodology employed draws mainly from the time series econometric literature. Formal tests are undertaken on economic time series to discern a stationary from a non stationary series. Augmented Dickey and Fuller (1979 and 1981) tests are performed to detect for the presence or not of unit roots. Regressions of the following form are typically used to test for the presence of a unit root.

$$
\Delta y_{t}=a_{0}+\gamma y_{t-1}+a_{2} t+\sum_{i=2}^{p} \beta_{i} \Delta y_{t-i+1}+\varepsilon_{t}
$$

The parameter of most interest is $\gamma$, if $\gamma=0$ the $\left\{y_{t}\right\}$ sequence contains a unit root. This regression is estimated using OLS. The estimated value of $\gamma$ and its standard error, allows for the calculation of a t-statistic which is compared to a critical value reported in the Dickey-Fuller tables. This comparison enables the acceptance or rejection of the null hypothesis $\gamma=0$.

This regression can be performed without an intercept and/or time trend. The Dickey-Fuller critical values of the t-statistics depend on whether the deterministic regressors $a_{0}$ and/or $a_{2}$ are included. The preliminary tests reported include a deterministic time trend. The critical values also depend on the size of the sample. These critical values, however, are unchanged by the presence or not of the autoregressive terms, where p equals the number of lags included. The number of lags is selected according to Akaike Information Criterion (AIC) due to the small sample size. Finally, $\varepsilon_{t}$ is a white noise error term.

\section{Panel Unit Root Methodology}

Monte Carlo simulations have shown that Dickey-Fuller tests have little power to discern among series with near unit roots and unit root series. One way to increase the power is to form a panel set, that is, to pool the estimates from a number of similar time-series and test the pooled value. Given a sample of $\mathrm{N}$ cross section units observed over $\mathrm{T}$ periods perform an Augmented Dickey Fuller (ADF) test of the following form.

$$
\Delta y_{i t}=a_{i 0}+\gamma_{i} y_{t-1}+a_{i 2} t+\sum_{j=1}^{p_{i}} \beta_{i j} \Delta y_{i t-j}+\varepsilon_{i t}
$$


Where $i=1 \ldots . . N, \quad t=1 \ldots . . T$, and $y_{i t}$ is the relevant variable for country $i$ at time $t$. The null hypothesis is that the stochastic process $y_{i t}$ follows a non stationary process. The three panel unit root test procedures used in this paper are following Im, Pesaran and Shin (2002).

The (IPS) procedure basically tests the significance of the sample mean of the t-statistics obtained from the N cross-section units. From the $\bar{t}$, a sample $Z_{\text {tbar }}$ is constructed which under the null, follows an asymptotic standardized normal distribution. The null hypothesis of this test (IPS) is $\gamma_{i}=0$, for $i=1 \ldots . . N$. The alternative hypothesis is that at least one value of $\gamma_{i}$ is different from zero. The critical value of this test depends on $\mathrm{N}, \mathrm{T}$ and the presence or not of a time trend. If a time trend is included in one regression it should be included in all regressions. Lags, however, can differ across cross section units Maddala and Wu (1999).

The Fisher $P_{\lambda}$ test of Maddala and $\mathrm{Wu}$ (MW) pools the P-values for each of the $\mathrm{N}$ independent ADF regressions and tests the significance of the pooled value according to a $\chi^{2}$ distribution with $2 \mathrm{~N}$ degrees of freedom. This test has the same null and alternative hypotheses of (IPS) and also allows for different lags across equations.

Levin, Lin and Chu (2002).

The test of Levin, Lin and Chu (LLC) imposes the more restrictive alternative hypothesis of an identical first order autoregressive coefficient, that is, $\gamma_{1}=\gamma_{2}=\ldots \ldots \gamma_{N}=\gamma$. Thus, the null hypothesis is that the series for all economies follow a unit root process, $(\gamma=0)$ whereas the alternative is that all series in the panel are stationary $(\gamma<0)$. Hence, the LLC test is more stringent than the IPS procedure. The critical values exhibit nonstandard distributions and are calculated using Monte Carlo simulations.

The three tests outlined above require that all series in the panel are independently generated. The error term must be not only contemporaneously uncorrelated but serially uncorrelated. Appropriate lag structure ensures zero autocorrelation of the regression residuals and still observe contemporaneous correlation of the residuals. A common procedure to induce independence is to subtract a cross-section average $y_{t}=(1 / n) \sum_{i=1}^{n} y_{i t}$ from the data. This procedure basically removes stationary common time specific effects in the error structure that accounts for simultaneous cross correlations among economies.

However, considering that shocks may impact economies differently, subtracting a common time specific effect may be exceedingly restrictive. Moreover, Maddala and Wu (1999) and O'Connell (1998) show that contemporaneous and serial correlation may bias the results. Bootstrapping techniques offer the advantage of not depending on the distributional hypothesis of Dickey-Fuller and of accommodating more general forms of correlation than time specific effects.

\section{PRELIMINARY RESULTS}

All the tables show the time series behavior of the relevant variable from indicated countries, descriptive statistics, panel unit root test results and a graphical behavior of the mean and standard deviation.

\section{Properties Of Real GDP Per Capita (RGDPL)}

Formal unit root tests are capable of establishing different stochastic properties. According to table IA, miracle countries exhibit at least one unit root according to IPS, LLC and MW. For growth disasters LLC rejects the null of a unit root at the 0.001 level and IPS rejects the null at a 0.0617 . MW rejects the null of a unit root at a 0.1273 level for growth disasters. Further research is needed to determine if growth miracles real GDP has two unit roots. 
The ADF test of the mean sequence fails to reject the null of a unit root for both groups of countries. However, for growth disasters the mean series is stationary at levels of less than $11 \%$. Moreover, the mean series for growth disasters is mostly negative, whereas, for growth miracles are uniformly positive.

Table IB, shows that panel unit root tests are incapable of rejecting the null of a unit root for super miracles and super disasters Real GDP per capita. However, the unit root of the super miracles is positive and for super disasters is negative. A similar conclusion can be drawn for the mean. Table IC, shows that mini disasters RGDPL are stationary, whereas mini miracles exhibit a unit root. Similarly, the RGDPL mean is stationary for mini disasters and has at least one unit root for mini miracles.

\section{Properties Of The Real GDP Per Capita Growth Rate (GRRGPDL)}

All tests, not shown, suggest that the GRRGDPL time series is stationary for miracles and disasters. However, the means appear to be different. The mean for disaster cases is negative $1 \%$, whereas for miracles is positive 5.03\%. Although the growth rate of real GDP per capita is stationary for both groups, further testing is bound to indicate significant mean differences. Additional testing needs to be performed for the subgroups of mini disasters, mini miracles, super disasters and super miracles.

\section{Properties Of Population (POP)}

Overall results, not shown, suggest that population series are non stationary for miracles and disasters. However, the LLC test suggests first difference for disaster still has a unit root, whereas first difference for miracles is stationary. Moreover, looking at the mean growth rate of the population, Table II, for disasters the series is stationary, whereas for miracles has a negative unit root. The evidence on population in particular the growth rate behavior is consistent with the notion that increased wealth reduces population growth. Increased wealth may be a very important factor inducing the third phase of demographic transition, Ray (1998)

\section{Properties Of Consumption (KC)}

For miracles and disasters, table III A the consumption series are stationary according o panel unit root tests, nonetheless, miracles consumption, as a percent of GDP, portrays a clear tendency to decrease. All panel unit root tests of super disasters, table III B, suggest stationary consumption series, whereas, all panel unit root tests of super miracles fail to reject the presence of a negative unit root.

Comparison of mini disasters and mini miracles, table III C, also suggest important differences. Mini disasters consumption is non stationary whereas mini miracles consumption is stationary. Moreover, the mean for mini disaster appears to be non stationary, whereas, for mini miracles is stationary at a significance level of 5\% percent. Finally, according to the standard deviation measure consumption appears to be more volatile for disasters than miracles.

Overall, the evidence indicates that consumption as a percent of GDP if it has a tendency is to decrease over time for miracles. This behavior is consistent with the predictions of Ramsey (1928) and empirical evidence across countries, Barro and Sala-i-Martin (2004).

\section{Properties Of Investment (KI)}

Panel unit root tests suggest that investment, as a percent of GDP, is stationary for miracles and disasters, not shown. ADF tests, however, indicate that the mean over time displays non stationary behavior for both groups with a tendency to increase for miracles. Moreover, miracles invest on average almost $25 \%$ of their GDP, whereas, disasters invest less than $8 \%$ of their GDP. In addition, investment is more volatile for miracles than disasters as measured by standard deviation. 
Panel tests, table IV, uniformly suggest that mini miracles investment series is stationary, whereas, LLC and MW indicate the presence of a unit root for mini disasters. ADF test is unable to reject the presence of a unit root in the mean series for mini disasters. However, a unit root is rejected at the $6.8 \%$ level for mini miracles mean series which exhibits if any increasing behavior.

\section{Properties Of Government Expenditures (KG)}

Based on panel unit root tests for disasters, government expenditures is a non stationary series, whereas, for miracles panel tests uniformly reject the null of a unit root, table V-A. Although, the behavior of the mean for both groups is non stationary according to ADF tests, for miracles the mean is clearly decreasing over time. Moreover, government expenditures exhibit greater volatility for disasters than miracles. In line with the overall results, mini disasters government expenditures is non stationary and mini miracles is stationary, Table V-B. Similarly, mean behavior over time is decreasing for mini miracles and non stationary for both groups. This evidence supports theoretical developments such as in Barro (1990) and is consistent with findings of less growth associated with greater government expenditures as in Knack and Keefer (1995), Barro (1997) and Gwartney, Holcombe and Lawson (1998).

\section{Properties Of Openness (OPENK)}

For disasters, table VI, panel unit root tests reject the presence of a unit root. For miracles, tests strongly suggest non stationary behavior. In the case of miracles, the presence of a unit root in the mean series can be rejected at the $5.4 \%$, whereas, for disasters the mean series contains a unit root. Nonetheless, the mean has a tendency to increase for miracles. Interestingly, miracles trade volume is more volatile than disasters and is also greater. This evidence is consistent with empirical findings indicative of a positive correlation between growth and trade volume. Moreover, the overall evidence suggests that the causality relation is from trade to growth, Lindert and Williamson (2001).

\section{FUTURE RESEARCH AND CONCLUSIONS}

Campbell and Perron (1991), show that misspecification problems, concerning deterministic regressors, affect the power of the test. Too few or too many deterministic regressors can induce failure to reject the null hypothesis of a unit root. To determine the stochastic regressors consistent with the data-generating process we will follow the procedure suggested by Dolado, Jenkinson and Sosvilla-Rivero (1990). Once for every sequence, associated with a specific group, appropriate deterministic regressors have been determined; panel unit root tests will be performed on group of countries with the same deterministic regressors.

In addition, there are sequences that have not been segmented in the four subgroups of mini miracles, mini disasters, super miracles and super disasters. Additionally, tests on variables such as inflation, nominal exchange rate and fiscal deficits could cast light on policy implications and discriminating stochastic properties. A control group comprised of countries with GDP per capita growth rates close to the world average of $1.8 \%$ could suggest important insights on stochastic properties differences.

It is also worthwhile to examine why miracles, more successful economies' investment, and openness variable apparently present more volatility than disasters? Similarly, why consumption and government expenditures appear to be more stable for miracles?

Preliminary findings of this research suggest significant stochastic properties differences between growth miracles and growth disasters. Miracles' real GDP per capita exhibit at least one unit root whereas disasters' is either stationary or has a negative unit root. Average growth rates appear to be significantly different. Average population growth rate is stationary for disasters, for miracles the existence of a negative unit root cannot be rejected. Consumption for miracles is either stationary or tends to decline, for disasters is stationary or tends to increase. Investment average and volatility are apparently significantly greater for miracles. Government expenditures for disasters are non stationary, for miracles are stationary with an incipient tendency to decline. Moreover, average 
government expenditures apparently are greater and more volatile for disasters. Finally, openness is stationary for disasters and for miracles it has at least one unit root.

\section{REFERENCES}

1. Barro Robert (1990). Government Spending in a Simple Model of Endogenous Growth. Journal of Political Economy, 98.

2. $\quad$ Barro, Robert (1999) Determinants of Economic Growth, MIT Press.

3. Barro Robert and Xavier Sala-i-Martin (2004) Economic Growth. MIT Press, Second Edition.

4. Campbell, John and Pierre Perron, (1991). Pitfalls and Opportunities: What Macroeconomists Should Know About Unit Roots. Technical Working Paper 100, NBER.

5. Doldado, Juan, Tim Jenkinson, and Simon Sosvilla-Rivero, (1990). Cointegration and Unit Roots. Journal of Economic Surveys 4.

6. Dickey, David and Wayne Fuller, (1979). Distribution of the Estimates for Autoregressive Time Series with a Unit Root. Journal of the American Statistical Association 74.

7. Gwartney, James, Robert Lawson, and Randall Holcombe (1998) The Size and Functions of Government and Economic Growth Joint Economic Committee, U.S. Congress.

8. Im, K, M. H. Pesaran, and Y. Shin (1996). Testing for Unit Roots in Heterogeneous Panels. Working Paper, University of Cambridge.

9. Jones, Charles (2002). Introduction to Economic Growth Norton, Second Edition.

10. Knack, Stephen and Philip Keefer (1995). Institutions and Economic Performance: Cross-Country Tests Using Alternative Institutional Measures. Economics and Politics, 7.

11. Levin, Andrew, Chien-Fu Lin, and Chia-Shang Chu (2002). Unit Root Tests in Panel Data: Asymptotic and Finite-Sample Properties. Journal of Econometrics 108.

12. Lindert, P. and J. Williamson (2001). Globalization: A Long History. Paper prepared for the Annual Bank Conference on Development Economics-Europe conference. World Bank, Europe-Barcelona. June 25-27

13. Maddala, G. S. and Shaowen Wu, (1999). Comparative Study of Unit Root Tests with Panel Data and a New Simple Test. Oxford Bulletin of Economics and Statistics 61.

14. Ramsey, Frank (1928). A Mathematical Theory of Saving. Economic Journal, 38.

15. Ray, Debraj (1998). Development Economics. Princeton University Press. 
Table I A

Real GDP Per Capita Series: RGDPL

DISASTERS

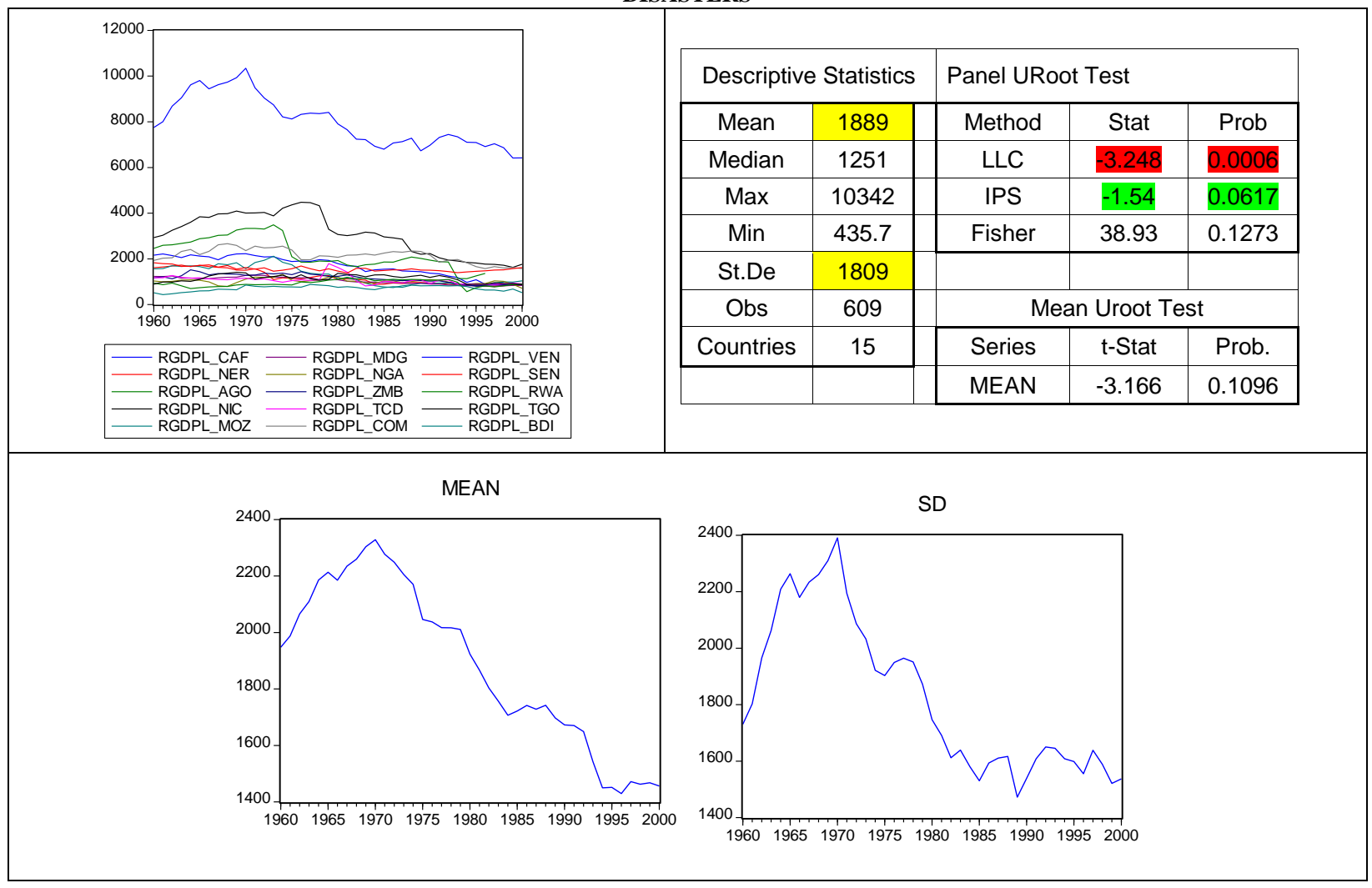


MIRACLES

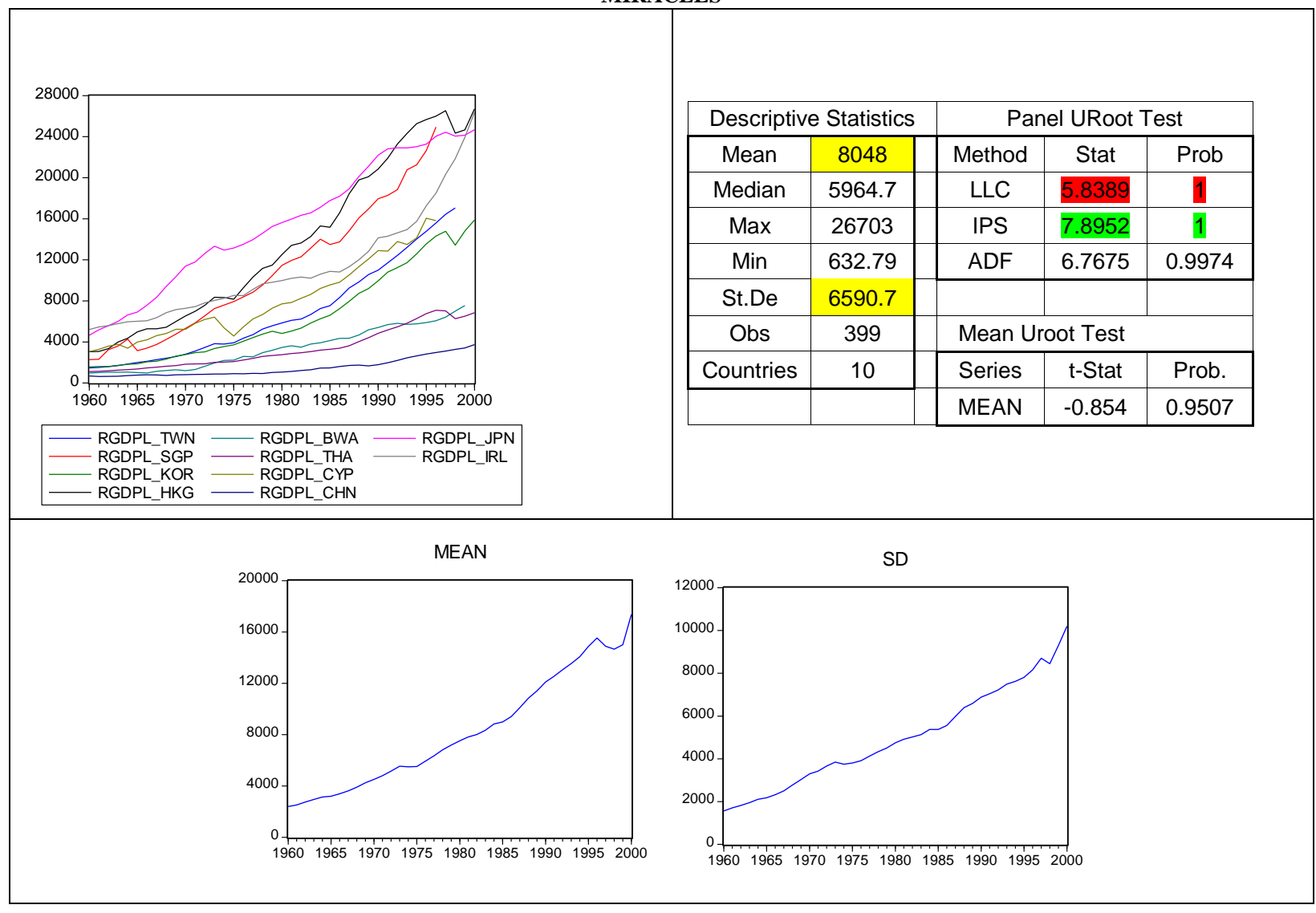


Table I B

Real GDP Per Capita Series: RGDPL

\section{SUPER DISASTERS}

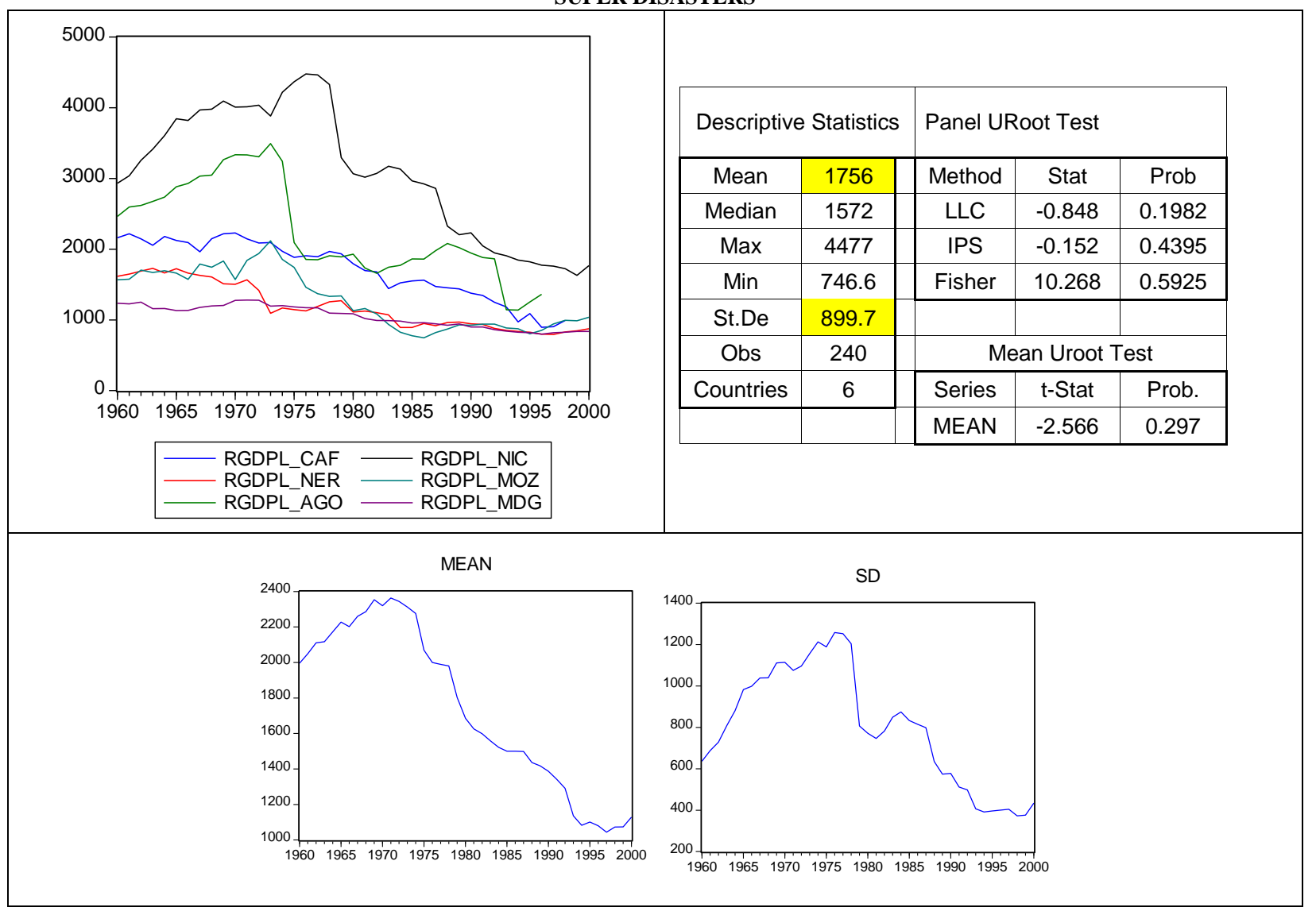

SUPER MIRACLES

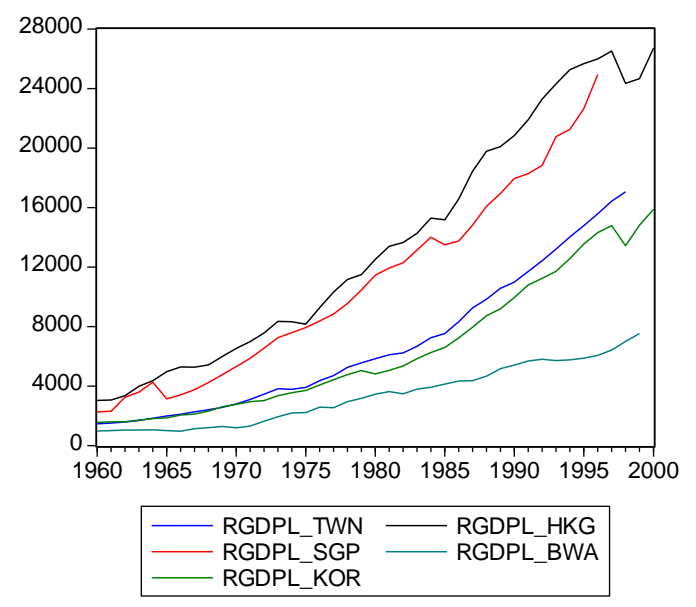

\begin{tabular}{|c|c|c|c|c|}
\hline \multicolumn{2}{|c|}{ Descriptive Statistics } & \multicolumn{3}{|c|}{ Panel URoot Test } \\
\hline Mean & 8201.3 & Método & Stat & Prob \\
\hline Median & 5848.6 & LLC & 1.069 & 0.8575 \\
\hline Max & 26703 & IPS & 3.3682 & 0.9996 \\
\hline Min & 973.52 & ADF & 3.251 & 0.9749 \\
\hline St.De & 6558.6 & & & \\
\hline Obs & 198 & \multicolumn{3}{|c|}{ Mean Uroot Test } \\
\hline Countries & 5 & Series & $\mathrm{t}$-Stat & Prob. \\
\hline & & MEAN & -1.342 & 0.8613 \\
\hline
\end{tabular}




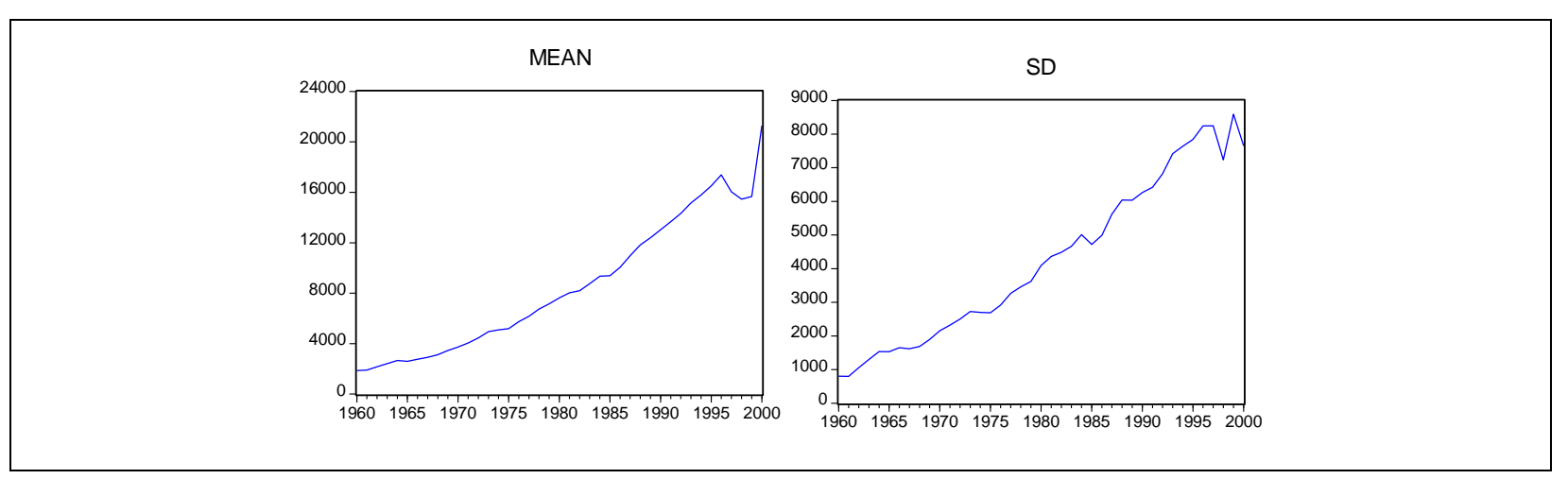

Table I C

Real GDP Per Capita Series: RGDPL

MINI DISASTERS

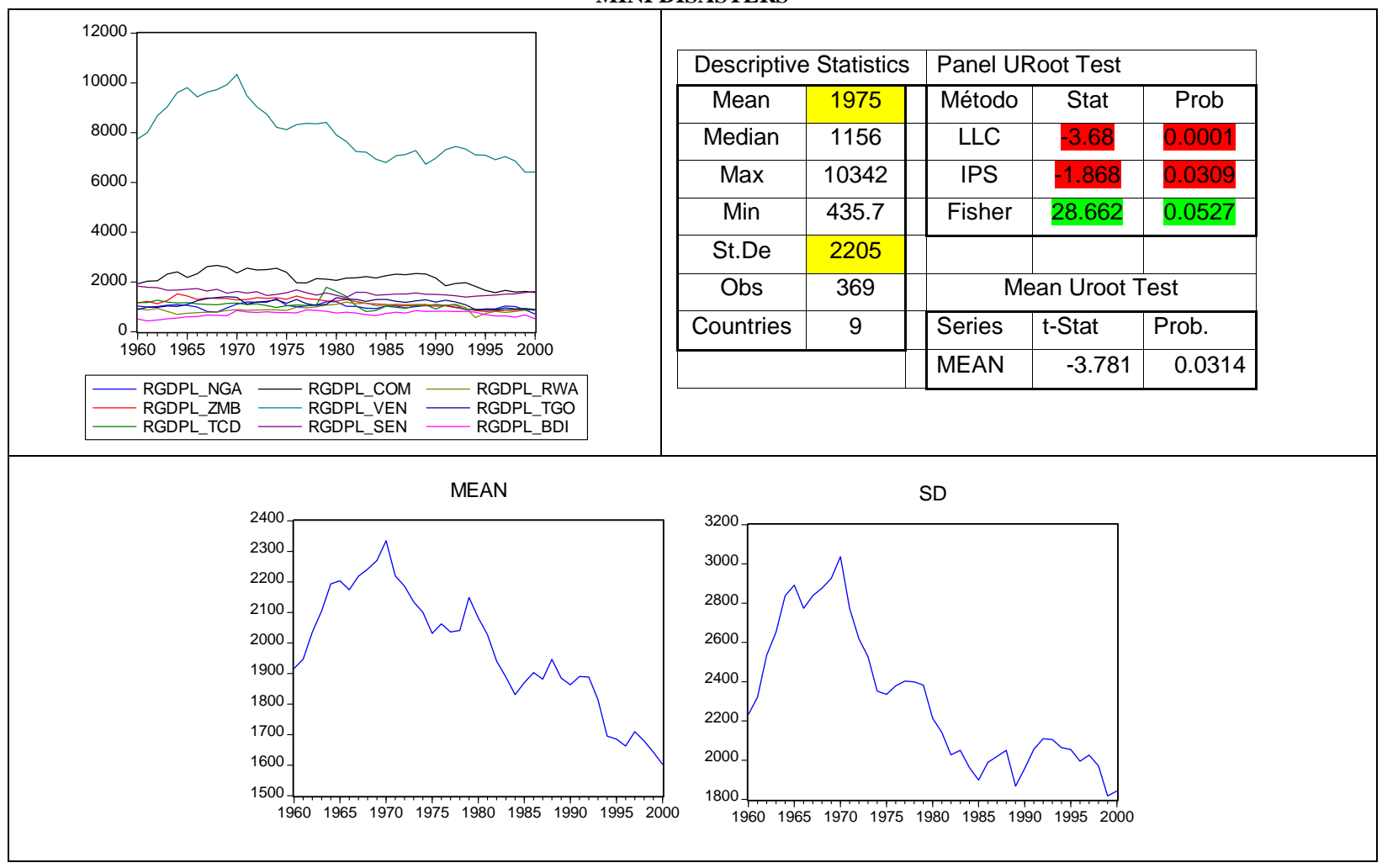




\section{MINI MIRACLES}

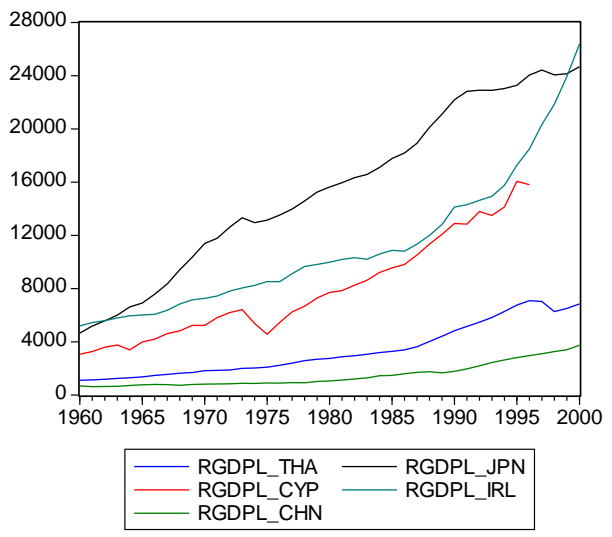

\begin{tabular}{|c|c|c|c|c|}
\hline \multicolumn{2}{|c|}{ Descriptive Statistics } & \multicolumn{3}{|c|}{ Panel URoot Test } \\
\hline Mean & 7897 & Método & Stat & Prob \\
\hline Median & 6074.6 & LLC & 7.2305 & 1 \\
\hline $\operatorname{Max}$ & 26379 & IPS & 7.8145 & 1 \\
\hline Min & 632.79 & ADF & 3.5166 & 0.9665 \\
\hline St.De & 6635 & & & \\
\hline Obs & 201 & \multicolumn{3}{|c|}{ Mean Uroot Test } \\
\hline Countries & 5 & Series & $\mathrm{t}$-Stat & Prob. \\
\hline & & MEAN & -0.021 & 0.9945 \\
\hline
\end{tabular}

Table II

Population POP

DISASTERS

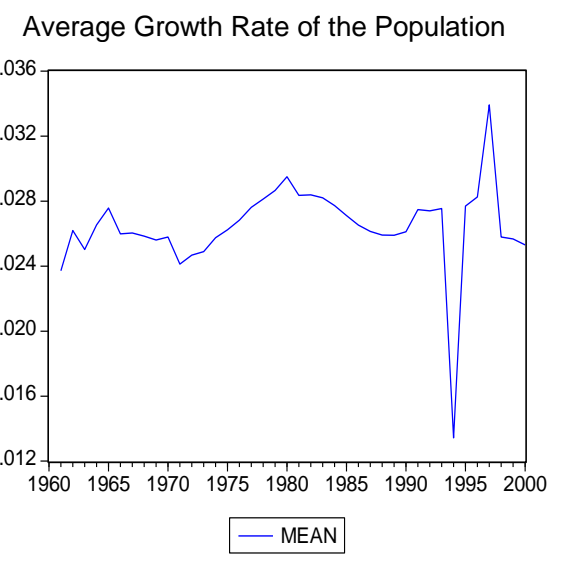

\begin{tabular}{|c|c|c|c|c|c|}
\hline & \multicolumn{5}{|c|}{ Panel URoot Test (Growth rate) } \\
\hline & \multicolumn{3}{|c|}{$\begin{array}{c}\text { Including a trend }(t) \text { as } \\
\text { a regressor }\end{array}$} & \multicolumn{2}{|c|}{$\begin{array}{l}\text { Without a trend } \\
(t)\end{array}$} \\
\hline & Method & Stat & Prob & Stat & Prob \\
\hline \multirow{3}{*}{ Level } & LLC & 1.2693 & 0.8978 & 0.0401 & 0.516 \\
\hline & IPS & -1.221 & 0.1111 & -2.486 & 0.0065 \\
\hline & Fisher & 55.036 & 0.0035 & 59.365 & 0.0011 \\
\hline & \multicolumn{5}{|c|}{ UR Test over the mean of the Growth } \\
\hline & \multicolumn{3}{|c|}{$\begin{array}{c}\text { Including a trend (t) as } \\
\text { a regressor }\end{array}$} & \multicolumn{2}{|c|}{$\begin{array}{l}\text { Without a trend } \\
(\mathrm{t})\end{array}$} \\
\hline & Method & Stat & Prob & Stat & Prob \\
\hline Level & ADF & -5.575 & 0.0002 & -5.652 & 0 \\
\hline
\end{tabular}

MIRACLES

Average Growth Rate of the Population

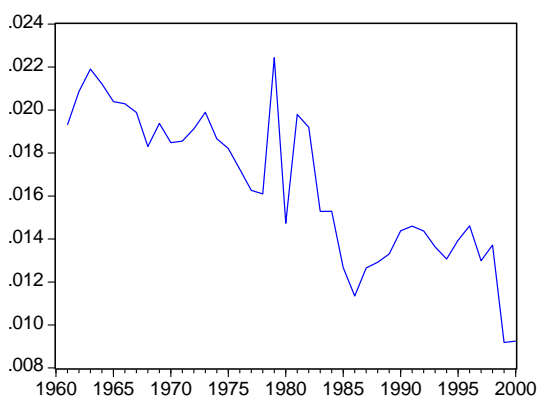
- MEAN

\begin{tabular}{|c|ccc|cc|}
\cline { 2 - 6 } \multicolumn{1}{c|}{} & \multicolumn{4}{|c|}{ Panel URoot Test (Growth rate) } \\
\cline { 2 - 6 } \multicolumn{1}{c|}{} & \multicolumn{2}{|c|}{$\begin{array}{c}\text { Including a trend (t) as } \\
\text { a regressor }\end{array}$} & \multicolumn{2}{c|}{$\begin{array}{c}\text { Without a trend } \\
(t)\end{array}$} \\
\cline { 2 - 6 } & Método & Stat & Prob & Stat & Prob \\
\hline \multirow{3}{*}{ Level } & LLC & -1.011 & 0.1561 & -1.686 & 0.0459 \\
& IPS & -2.942 & 0.0016 & -0.824 & 0.2051 \\
& Fisher & 52.988 & 0.0001 & 37.151 & 0.0112 \\
\hline
\end{tabular}

\begin{tabular}{|c|c|c|c|c|c|}
\hline & \multicolumn{5}{|c|}{ UR Test over the mean of the Growth } \\
\hline & \multicolumn{3}{|c|}{$\begin{array}{c}\text { Including a trend (t) as } \\
\text { a regressor }\end{array}$} & \multicolumn{2}{|c|}{$\begin{array}{l}\text { Without a trend } \\
(\mathrm{t})\end{array}$} \\
\hline & Método & Stat & Prob & Stat & Prob \\
\hline Level & ADF & -0.503 & 0.8796 & -4.923 & 0.0015 \\
\hline
\end{tabular}


Table III A

Consumption As Percent Of GDP, KC

DISASTERS

(19)

MIRACLES

(19) SD

Table III B

Consumption As Percent Of GDP, KC

\section{SUPER DISASTERS}

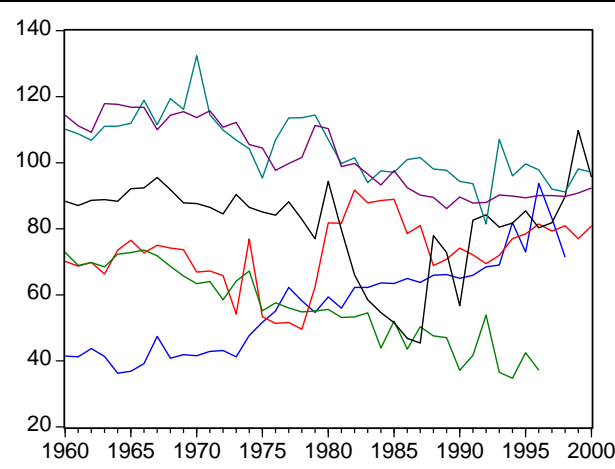

\begin{tabular}{|c|c|c|c|c|c|}
\hline \multicolumn{4}{|l|}{ Descriptive Statistics } & \multicolumn{3}{|l|}{ Panel URoot Test } \\
\hline Mean & 79.36 & & Method & Stat & Prob \\
\hline Median & 81.22 & LLC & -2.53 & 0.0057 \\
\hline Max & 132.4 & IPS & 42.629 & 0 \\
\hline Min & 34.75 & Fisher & 51.064 & 0 \\
\hline St.De & 22.46 & \multicolumn{3}{|c|}{} & \\
\hline Obs & 240 & \multicolumn{3}{|c|}{ Mean Uroot Test } \\
\hline Countries & 6 & & Series & t-Stat & Prob. \\
\hline & & MEAN & 0.3893 & 0.9985 \\
\hline
\end{tabular}




\section{SUPER MIRACLES}

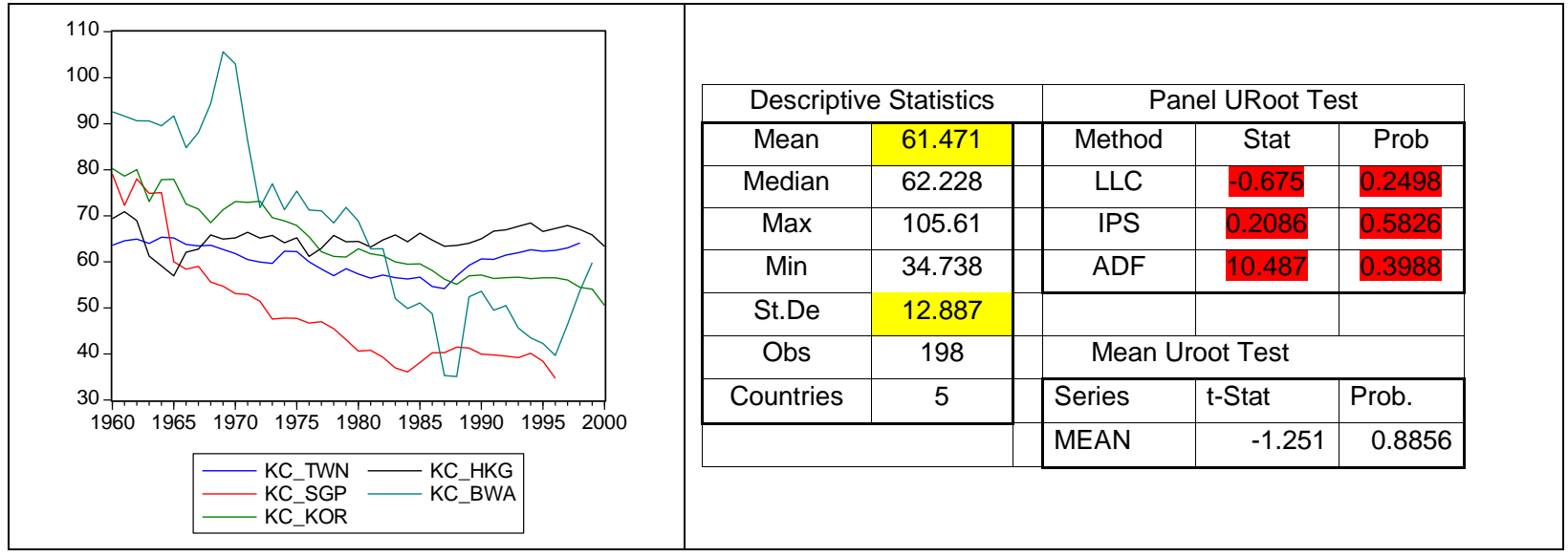

Table III C

Consumption As Percent Of GDP, KC

MINI DISASTERS

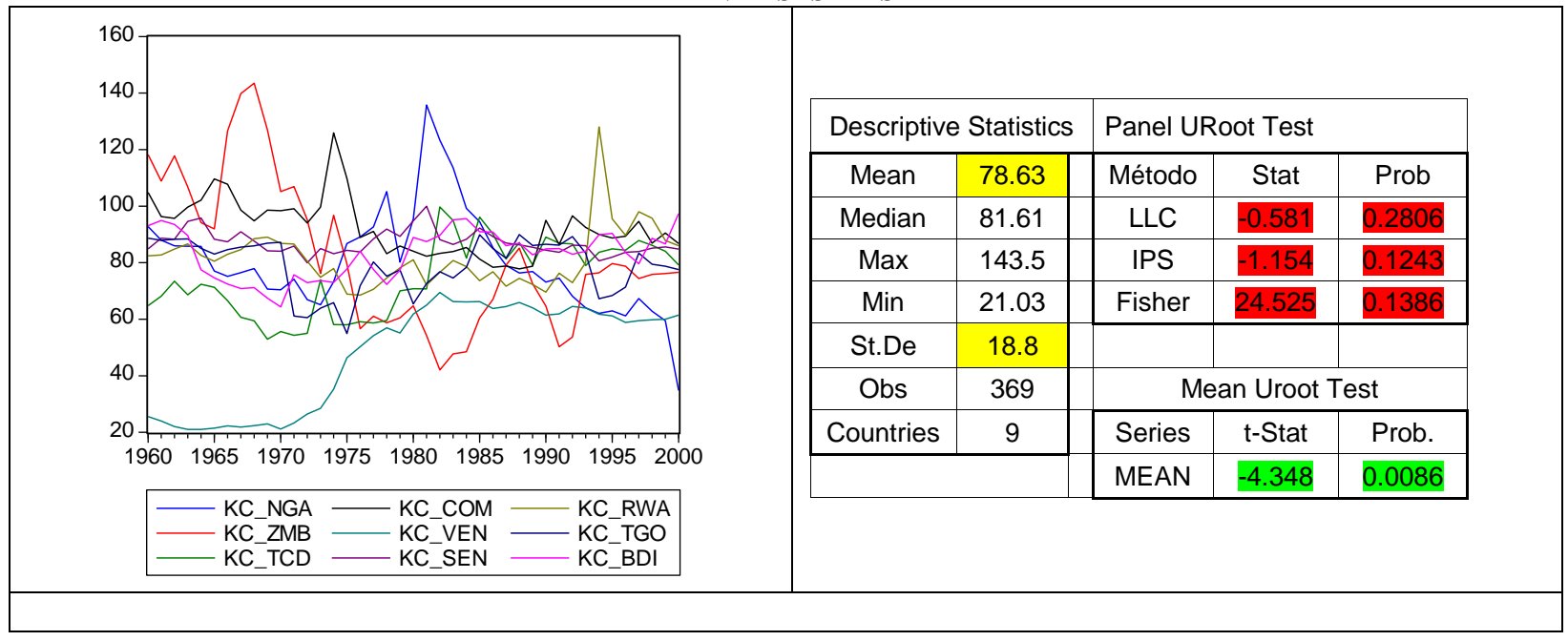




\section{MINI MIRACLES}

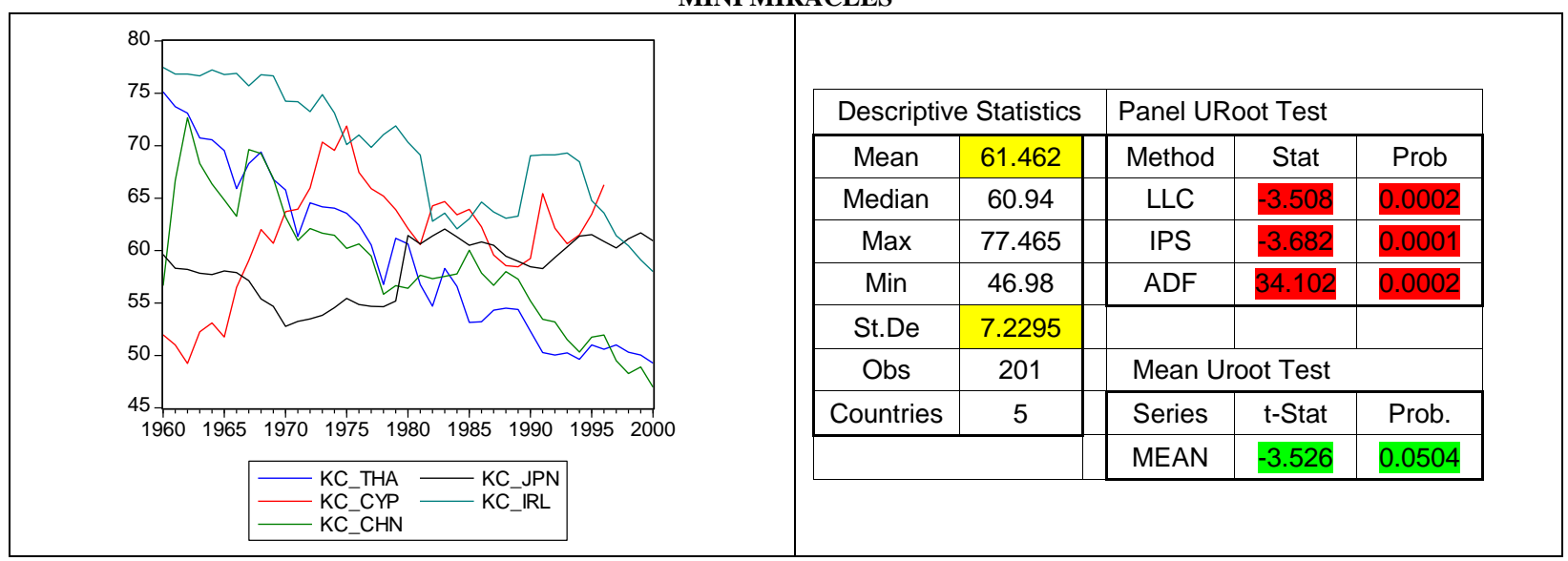

Table I V

Investment As A Percent Of GDP, KI

\section{MINI DISASTERS}

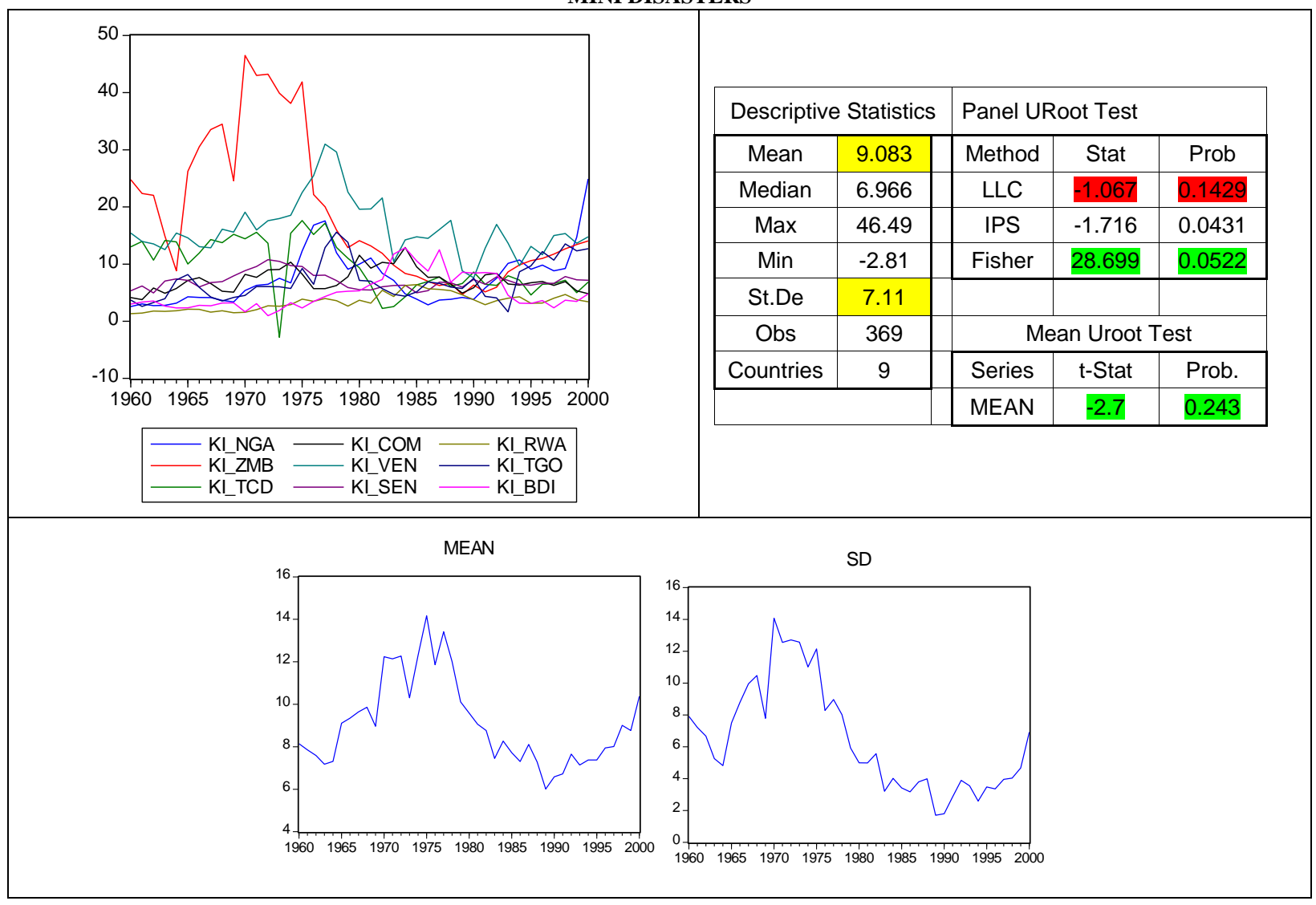




\section{MINI MIRACLES}

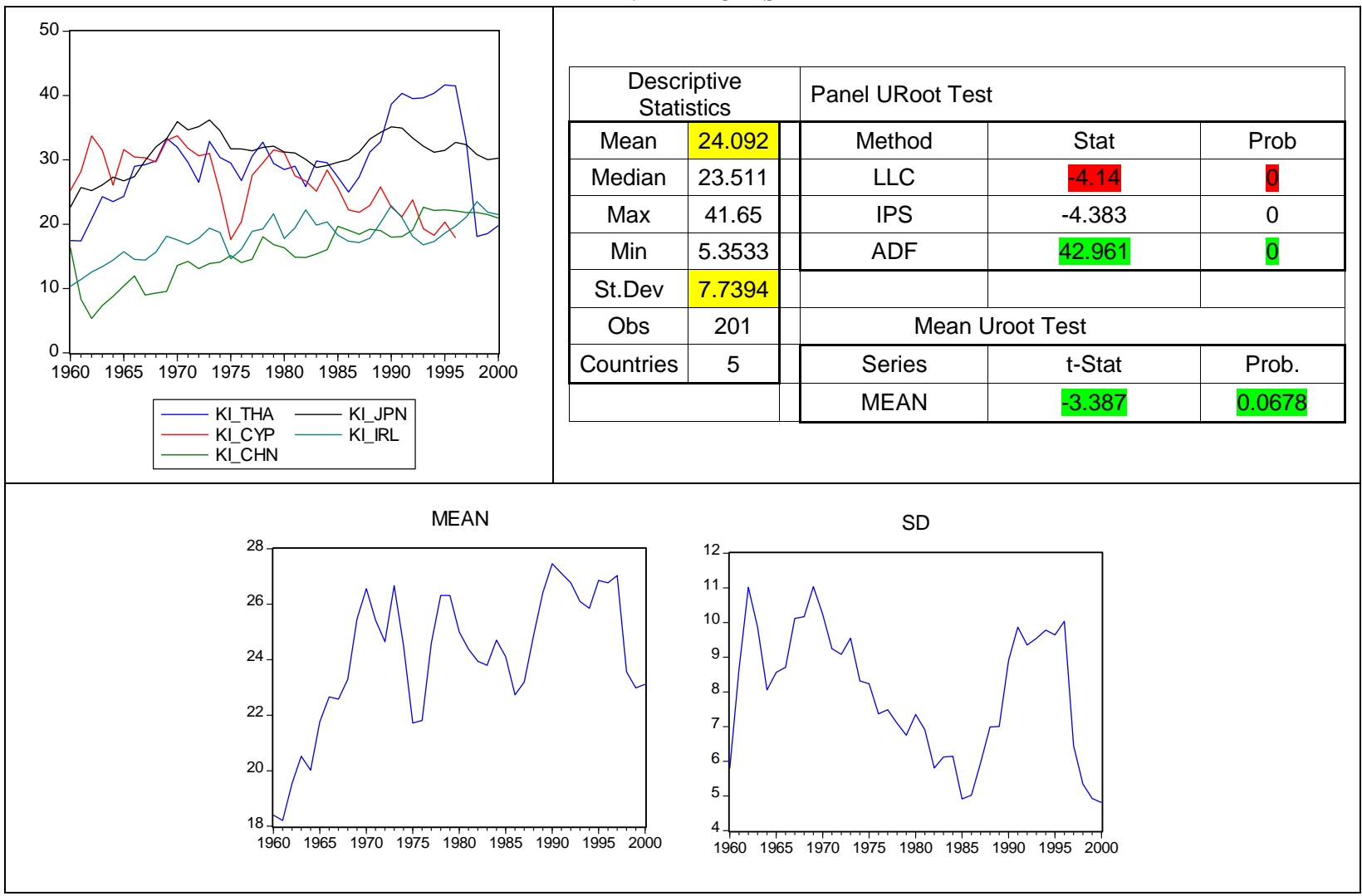

Table V A

Government Expenditures As A Percent Of GDP, KG

DISASTERS

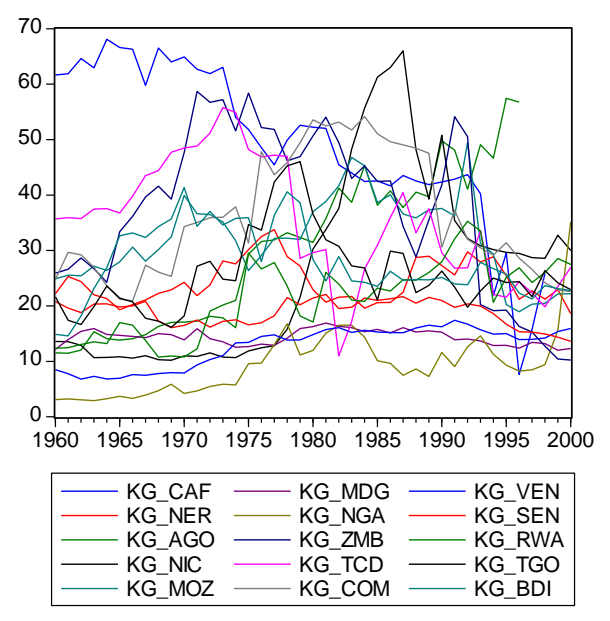

\begin{tabular}{|c|c|c|c|c|c|}
\hline \multicolumn{4}{|c|}{ Descriptive Statistics } & \multicolumn{3}{|l|}{ Panel URoot Test } \\
\hline Mean & 26.71 & & Method & Stat & Prob \\
\hline Median & 23.98 & LLC & 0.0498 & 0.5199 \\
\hline Max & 68.08 & IPS & -0.287 & 0.387 \\
\hline Min & 2.927 & Fisher & 36.724 & 0.1853 \\
\hline St.De & 13.97 & \multicolumn{3}{|c|}{} & \\
\hline Obs & 609 & & \multicolumn{3}{|c|}{ Mean Uroot Test } \\
\hline Countries & 15 & & Series & t-Stat & Prob. \\
\hline & & MEAN & 0.4262 & 0.9985 \\
\hline & & lag= & 9 & AIC \\
\hline
\end{tabular}




\section{MIRACLES}

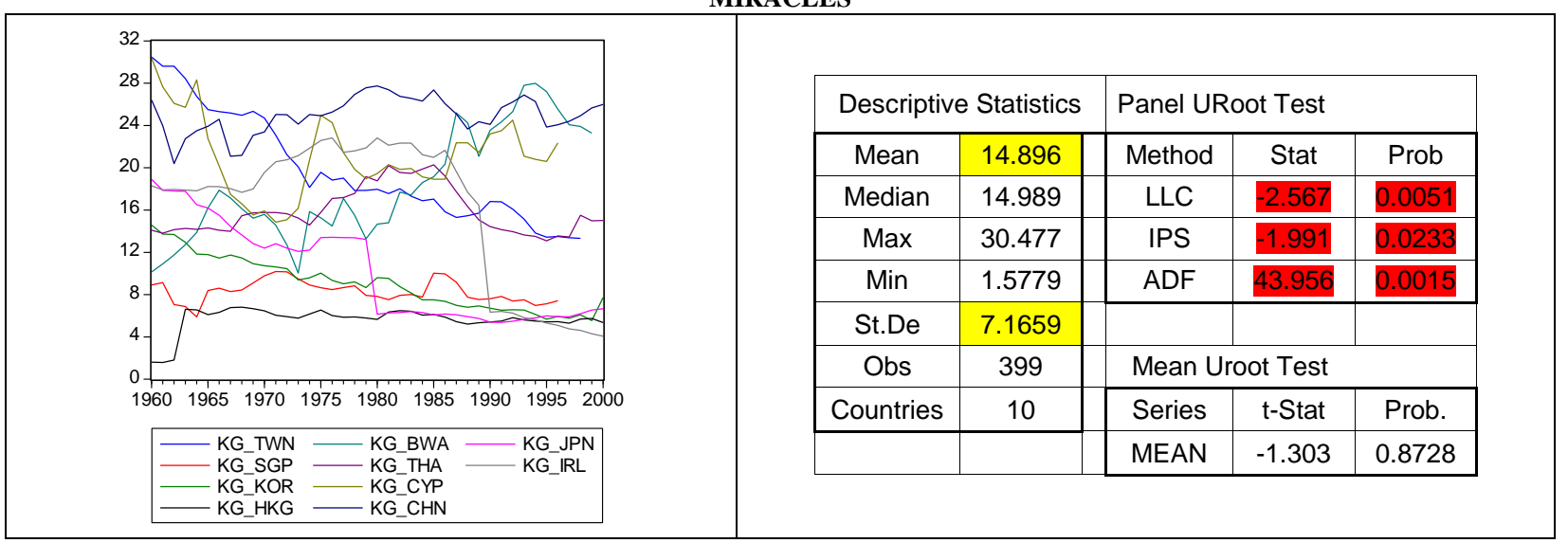

Table V B

Government Expenditures As A Percent Of GDP, KG

MINI DISASTERS

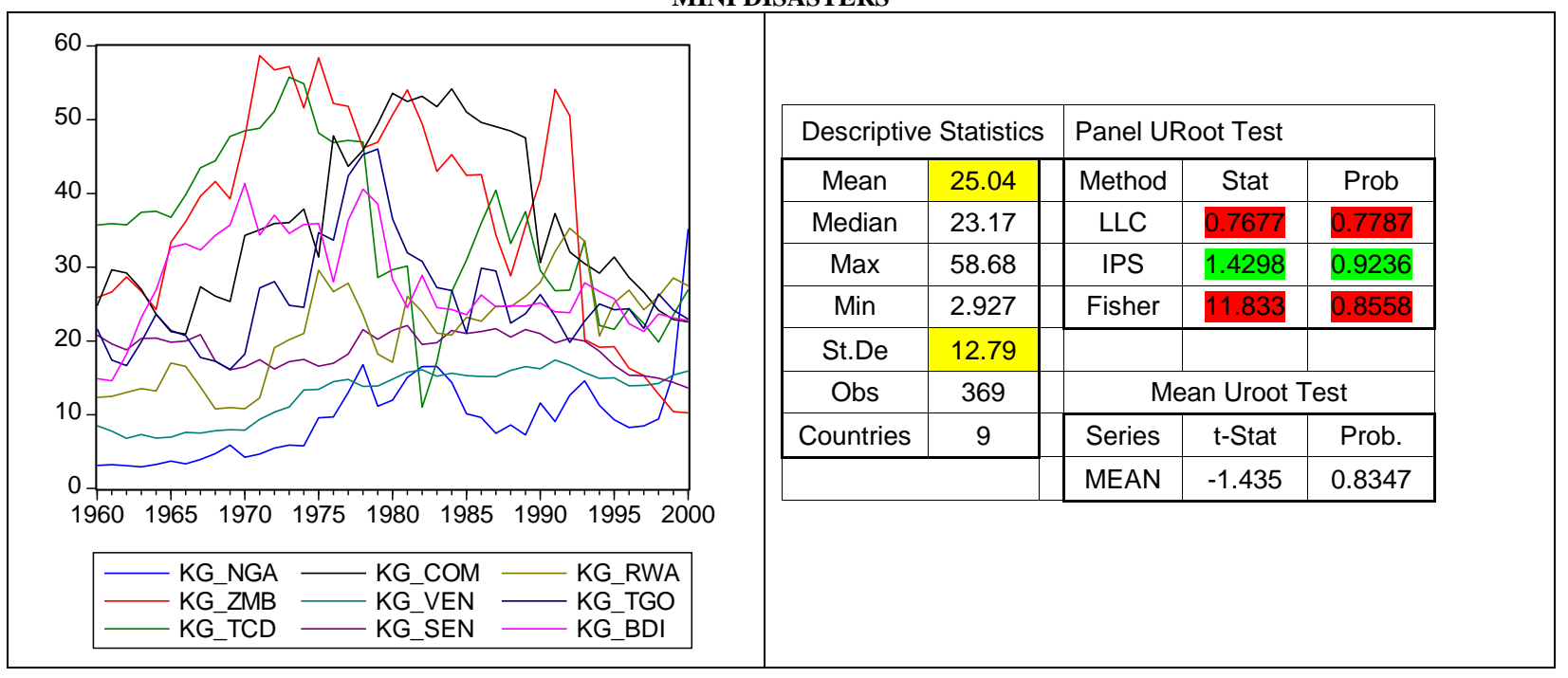


MINI MIRACLES

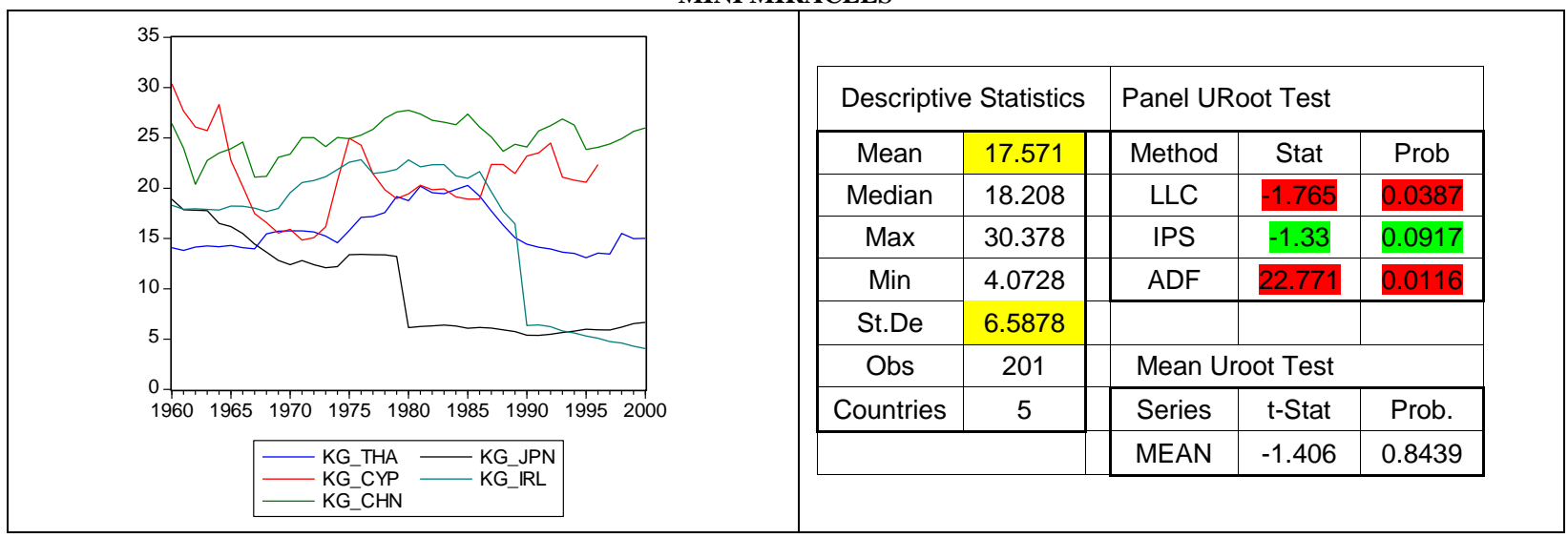

Table VI

Exports Plus Imports As A Percent Of GDP, OPENK

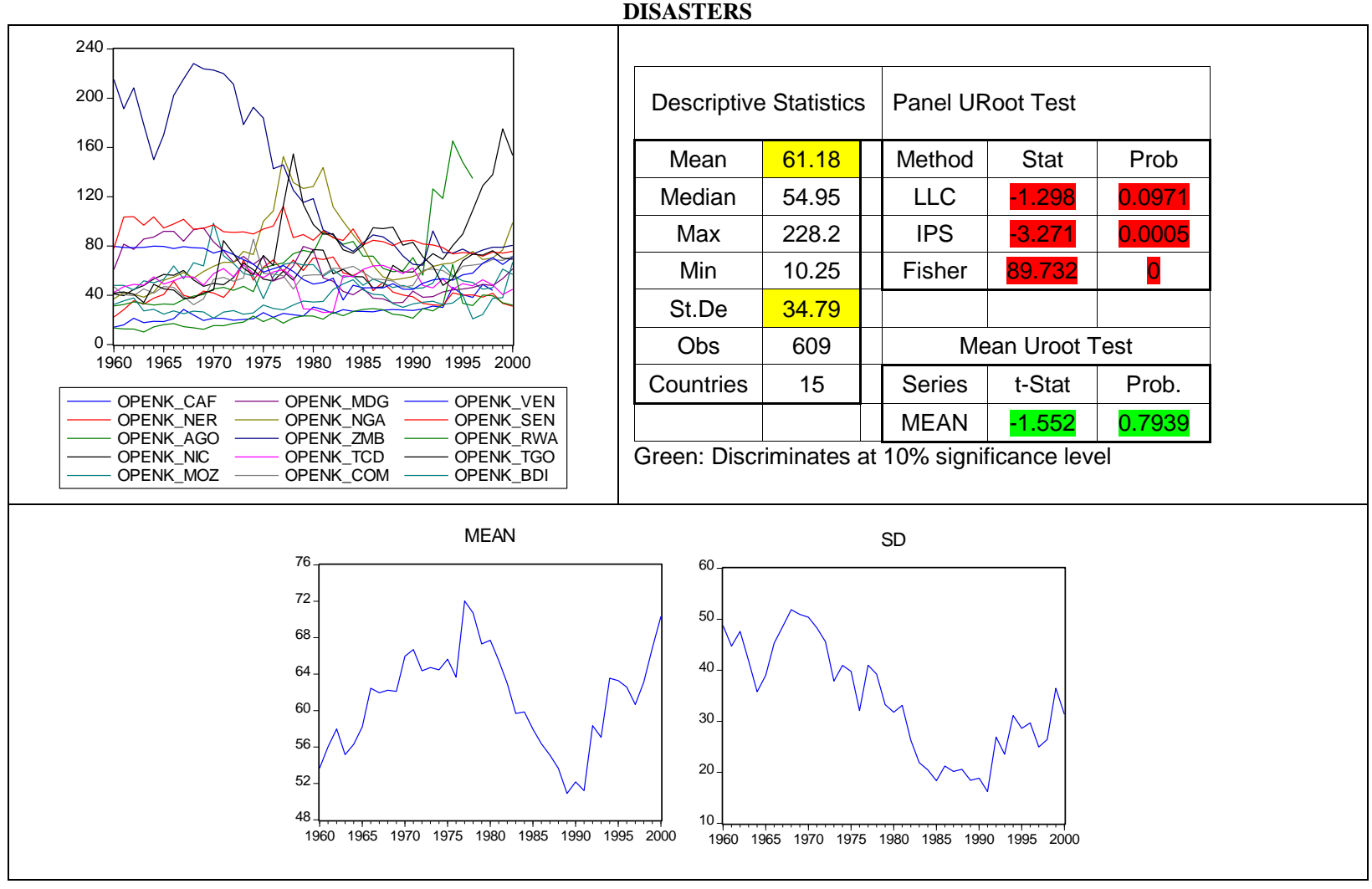


MIRACLES

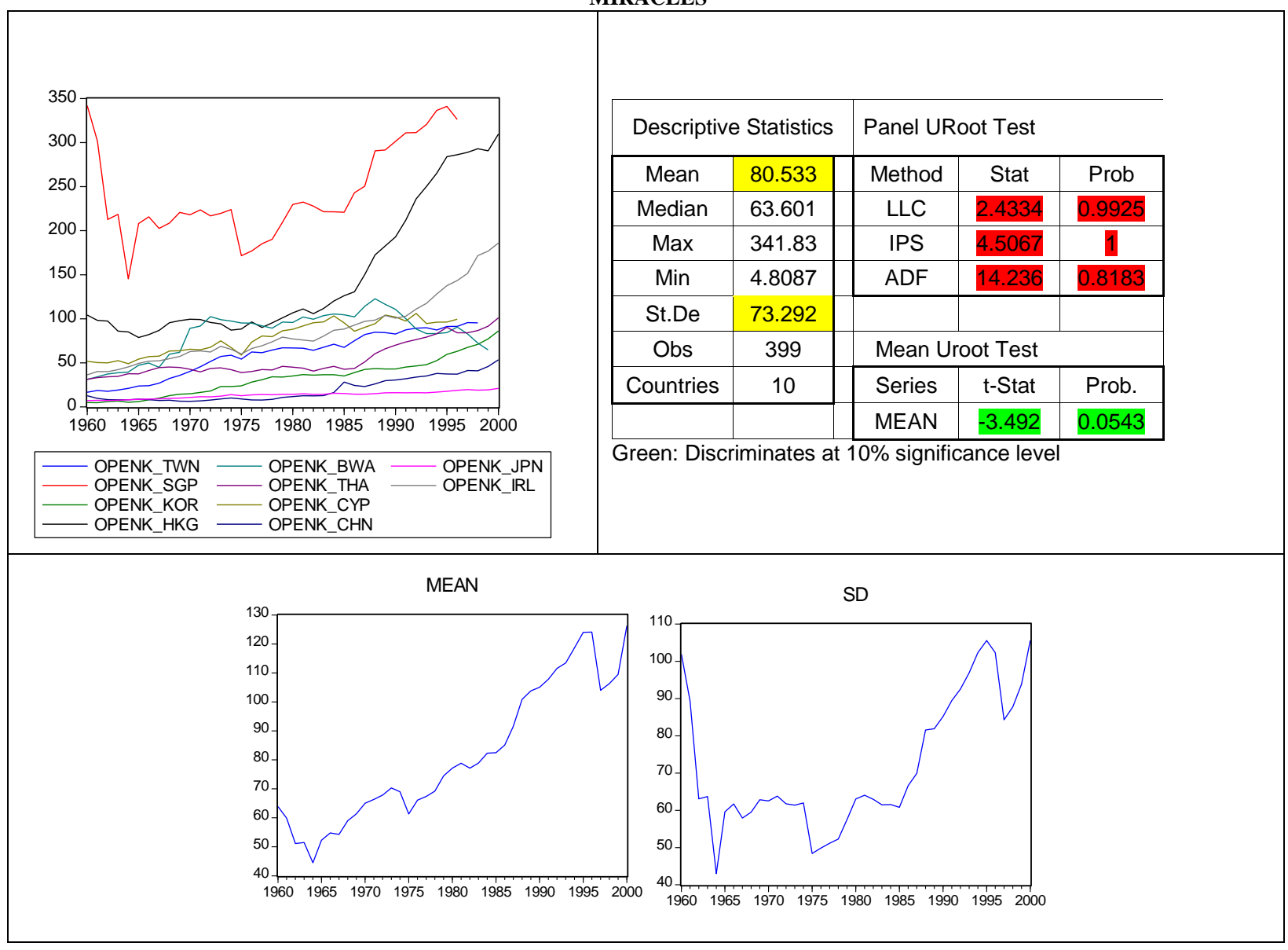

